\title{
Using Teacher Study Groups to Enhance Teaching Effectiveness of English Language Teachers in East Gojjam Zone
}

\author{
Mengistu Anagaw (MEd) Assefa Kinefergib \\ Debre Markos, Ethiopia May 2018
}

\begin{abstract}
Teachers' professional development is the core of educational improvement. The study investigated the role of participation in a Teacher Study Group in enhancing English language teachers teaching effectiveness by engaging them in a teacher study group and thereby designing teacher study group procedures that can enhance teaching effectiveness of teachers in the schools. Focus group discussion, document analysis and classroom observation were used as methods of data gathering. The teachers were engaged in a regularly customized TSG activities on the basis of Tripod 7Cs to investigate what they improve on their teaching effectiveness. A thematic crossover analysis is used to present the data.As learned from this case study, it is evident that the teacher's collegiality and open mindedness to involve in a dialogic TSG has improved. Moreover, as reflected by the teachers, their teaching effectiveness (as self-admitted and measured by Tripod 7Cs) has improved due to participation in TSG. This justifies the worth of a statement nearly a century ago that ' ...there is no workable alternative to working together, respectful of differences and eager to keep the conversation going." John Dewey, 1938). However, further studies should confirm the viability of TSG discussion focusing on verifying the statistical significance and dimensions of teaching effectiveness TSG brings before it is considered as an alternative CPD modality.
\end{abstract}

Keywords: TSG, Teaching Effectiveness, 7Cs

DOI: $10.7176 / \mathrm{JEP} / 10-7-02$

Publication date:March $31^{\text {st }} 2019$

\section{INTRODUCTION}

'...there is no workable alternative to working together, respectful of differences and eager to keep the conversation going. " John Dewey, 1938)

Learner centered education puts students at the center of learning while providing new and demanding roles for teachers' i.e. facilitating learning (Westwood, 2008) that requires much more than knowledge of the subject matter. For teachers, to cope with these demands, the need for quality and continuous professional development became resolute. Hence, teacher Continuous Professional Development efforts come into being as a result of change on perspectives of education and the resulting challenges on teachers which were difficult to address through one shot pre service trainings (Villegas-Reimers, 2003). Nowadays, different continuous professional development models are used to guide and encourage teachers improve their teaching effectiveness, surfacing inadequacy of pre service education and one-shot workshops.

In line with this, Sparks (2002) stipulates that high quality professional learning for educators and success of ambitious goals for students go hand in hand. Similarly, Villegas-Reimers (2003) argued that quality professional development can lead to quality outcomes such as the creation of a positive school culture, improvement in individual teacher skills, and development of opportunities for peer learning. Thus, the argument behind an ongoing learning is not because teachers need to "repair a personal inadequacy" as detailed by Jackson (1974) cited in Clarke and Hollingsworth (2002:948), but as a quest for "greater fulfillment as a practitioner of the art".

As of Akerson, McDuffie and Roth (2002) professional development is most successful when based on the issues of teachers. Teachers' ability to direct their own professional development is supported by research on teacher thinking, which suggests that "teachers are more active than passive, more ready to learn than resistant, more wise and knowledgeable than deficient, and more diverse and unique than they are homogeneous" (Clark, 1992: 76-77). On the top of that, Clair (1998:469) stated that "one professional development approach that is consistent with what is known about teaching, learning, and effective professional development is teacher study groups (TSGs)". A Teacher study group (TSG) is one among several forms of professional development activities often arranged by teachers to improve their skills through collaboration and reflection. Therefore, it is seen as a professional development context for teachers, to reflect on and learn from their practices. The need for teachers' active participation in their own professional development has initiated the rise of Inquiry Groups, usually known as Teacher Study Groups (Dash \& Jung, 2005). Research also indicates that teachers need to create their own groups for change by working collaboratively (Cochran-Smith \& Lytle, 1990). Hence, a teacher study group is a dynamic model of professional development that engages four to eight teachers interested in sharing and solving challenges and reflecting on practices. Study groups differ from traditional forms of professional development in that the group determines the content of the study based on student data, shared interests, or professional curiosity concerning a new theory or practice.

Teacher study groups are commonly practiced by teachers who share similar interests and desire to reach 
their professional goals, understand and share unavoidable struggles, confusions, and frustrations in the ongoing process of professional development. In other words, a study group is an opportunity, for teachers, to think over their beliefs, share ideas, challenge practices, blend theory and practice, and identify areas that need professional and pedagogical improvements. Knowledge, for teachers who adhere to this model of professional development, is not meant to be transmitted by experts, but concomitant with the constructivist notion of learning, cooperatively constructed (Yi-Ching Huang, 2007).

According to Birchak et al (1998) teacher study groups can take several forms comprising but not limited to Topic-Centered Groups, Teacher Research Groups, Professional Book Discussion Groups, Readers and Writers Groups and School-Based Groups. In a concise and comprehensive classification, Cayuso et al. (2004) refined this and came up with four teacher study group types which are highlighted as follows.

The adoption and success of teacher study groups depends on several factors. For instance, teachers feel that they are too busy to think about beginning a study group. According, Bomer (1995) the most common challenge in forming and maintaining study groups is time shortage though this technique is meant to address problems of this kind. Similarly, teachers' commitment and accountability measures are necessary for a study group to be effective. The extent to which a professional development content and/or strategies are integrated into classroom practice is may not be part of teacher evaluations, nor the performance assessment of those who select professional development activities which might imply negligence. Likewise, Sparks (2002) argues that school leaders through their actions or neglect; make significant differences on the quality of teachers learning. A community of teachers may form and learn together about teaching but be unable to make meaningful and lasting changes that positively alter the fabric of the school because of administrative, scheduling, or peer pressure obstacles. All these and other factors coupled with conceptual limitations teachers and principals exhibit, can adversely affects the success of teacher study groups.

In Ethiopia, failure in the quality of education has become a point of hot discussion for a decade or so. Teachers' weak professional quality is taken as the root cause for this and continuous professional development of teachers, in the form of portfolio keeping, has been the most widely adopted way out of the situation (MoE, 2009). In spite of this, in its perceived and felt community need assessment, Debre Markos University (2014) found that decreased teachers knowledge and skill and demotivation still persists as critical problems in the sector.

Recently, there has been an increased nationwide interest in the use of the Teacher Study Groups (TSG) or the Teacher Work Group as an approach to professional development. However, experience shows that its procedures are not cleared, its impact on quality of performance not empirically attested and accepted. Thus, the impetus behind this inquiry is to investigate the role of participation in a Teacher Study Group in enhancing teaching effectiveness of English language teachers in the Schools. In the school, teachers have been required to work in groups called 'change army' which I prefer to call study groups.

\section{Statement of the problem}

It is evident that every teacher must fine tune his or her teaching skills to meet the needs and abilities of students. In this respect, continuous professional development is considered as an essential mechanism for deepening teachers' content knowledge and developing their teaching practices in order to teach to high standards (Borko, 2004). However, for teachers lacking varied and adequate professional development support, setting up some kind of program is necessary to enable them explore their teaching and find solutions to problems.

Recently, the country has made a move towards 'a groups based work and learning' culture. On the contrary, though the educational institutions have been advocating the adoption of teacher and students study group, local empirical evidences that ascertain such efforts are hardly available. Moreover, the challenges and opportunities and procedures of running teacher study groups are not well documented. To that end, this inquiry explored the role of participation in a teacher study group in enhancing teaching effectiveness of teachers at schools. Thus, the inquiry engaged the teachers in a regularly customized TSG activities on the contents of the 7Cs to investigate what they improve on their teaching effectiveness. More specifically the study intended to:

1. Identify ways to improve teaching effectiveness of teachers in East Gojjam zone primary schools by engaging them in a teacher study group.

2. Adapt teacher study group procedures that can enhance teaching effectiveness of teachers in the schools.

\section{RESEARCH METHODOLOGY}

This study aims to engage teachers in a regularly customized TSG activities on the basis of Tripod 7C to investigate what they will improve on their teaching effectiveness in their real classrooms. Thus, a multiple case study design is used to fully address the research questions where qualitative data is secured through FGD, document analysis and classroom observations.

A case study is a research approach in which one or a few instances of a phenomenon are studied in depth via descriptive, exploratory or explanatory analyses (Creswell, 2007). Moreover, a case study is conducted when the focus is when behavior of participants cannot be manipulated and boundaries between the phenomenon and the context are not clear. Yin (2009) underpins that a multiple case study design enables replication to independently 
confirm emerging constructs and identify complementary aspects of the phenomenon under investigation by analyzing within and across settings. Thus, the decision to utilize multiple case study design emanated out of desire to investigate teachers' effectiveness improvements due to participation in a TSG.

This study participated English language teachers in four primary schools purposively selected based on accessibility and interest, to ensure lasting engagement. From a total of four schools selected, three completed the sixteen-week long TSG discussion. The total number of the teachers was four in Amanuel (Amanuel Number One Primary School), Six in Bichena (Hailu Yosedeq Primary School), Six in Dejen (Dejen Primary School) and Six in Debre Markos (Biruh Tesfa primary school). The schools are located in towns, yet access to alternative professional development opportunities is scanty.

Since researching teachers requires intensive involvement of the researcher and the researched (Valerie and Magdalena, 2008), this study employed focus group discussion as a major data gathering tool and document analysis (analysis on teachers reflective journals) and classroom observation as supporting tools to get a direct insight into the practice and impacts of participation in teacher study groups. The FGD provided the researchers with an insider perspective about the teachers lived and shared experiences on the relevance and appropriateness of teacher study groups as it unfolds. The TSG participants kept reflective logs that summarized their practices in the classroom and help them reflect on their experiences and report what they have learned. The reflective log helped to compare how teachers' perceptions change through a teachers' study group (Moreno and Palencia, 2001).

During TSG every teacher was given time to reflect on the issues raised. The issues agreed on were practiced by the teachers and its perceived effects were incorporated in their reflective logs. The TSG comprised interactive sessions held at the school sites every week from December 2017 to April 2018; each session took an hour on average. At the end of the TSG a session to debrief the overall practice and role of TSG was conducted. Each week's discussion started on the practice of an issue generated from the practice of previous week's conversation. All participants stated that they had trust in the study group format and it was a place to get answers and resolve issues concerning their teaching effectiveness.

The data was organized and analyzed thematically. The pre-questionnaire was designed to identify participants' expectations from TSG and their initial thoughts about TSG organization respectively. For Onwuegbuzie et al (2010) crossover analyses enables researchers go back and forth several times and present an analysis of data gathered through different tools thematically. In this study, a thematic crossover analysis will be used to present the data from the classroom observation, focus group discussion and document analysis.

\section{RESULTS AND DISCUSSION}

The study explored the role of participation in teacher study groups in enhancing the teaching effectiveness of primary school EFL teachers in East Gojjam zone. More specifically, the study attempted to adapt teacher study group procedures to improve teaching effectiveness of participating teachers.

In this study, twenty four to thirty two willful teachers in four schools were proposed but only 22 responded of which 16 teachers completed the program. The teachers from primary schools in Dejen, Amanuel and Bichena completed the TSG sessions while those in Debre Markos were subsequently absent after planning for TSG then stopped it.

\subsection{Preliminary survey}

The participants filled in a preliminary questionnaire intended to survey teachers' awareness and expectations about a TSG. The first section intended to record if teachers had the opportunity to any professional development activity.

Asked how they try to keep themselves up-to-date with changes and improvements in teaching teachers reported that they observe their colleagues class, read additional materials and share experiences of colleagues. They listed CPD and other short trainings as forms of professional development they participated.

Regarding the group size, majority of teachers stated it should be five to seven or less. The respondents suggested possible topics for TSG discussions including presenting and explaining content, effective teaching methods, skills and techniques (learning strategies and differentiating instruction along with needs of students) and classroom management, building positive rapport and motivation received a majority vote. This, fortunately resembles topics of Tripod 7Cs. The responses of teachers about the role of collegiality in teacher development indicate that participants were having a mix of ideas; some positive about working with colleagues and sharing knowledge and experiences on professional issues, which might have contributed to the positive responses from participants about the TSG while others showed their reservations.

\subsection{TSG Discussion on 7Cs of effective teaching}

The study engaged teachers in a weekly discussion on tripods 7Cs of effective teaching. The 7Cs is a reliable and valid measure of effective teaching. Hence, the 7Cs of effective teaching was discussed and debated in a TSG and agreed points were practiced in the participant teachers' classrooms. Moreover, the teachers documented the 
perceived effects of practicing principles of 7Cs in a reflective log on a weekly basis. The impacts of these practices and students reactions as well as teachers overall assessment of the change was included in the logs. Moreover, classroom observations were made in three classes to verify the findings from questionnaires.

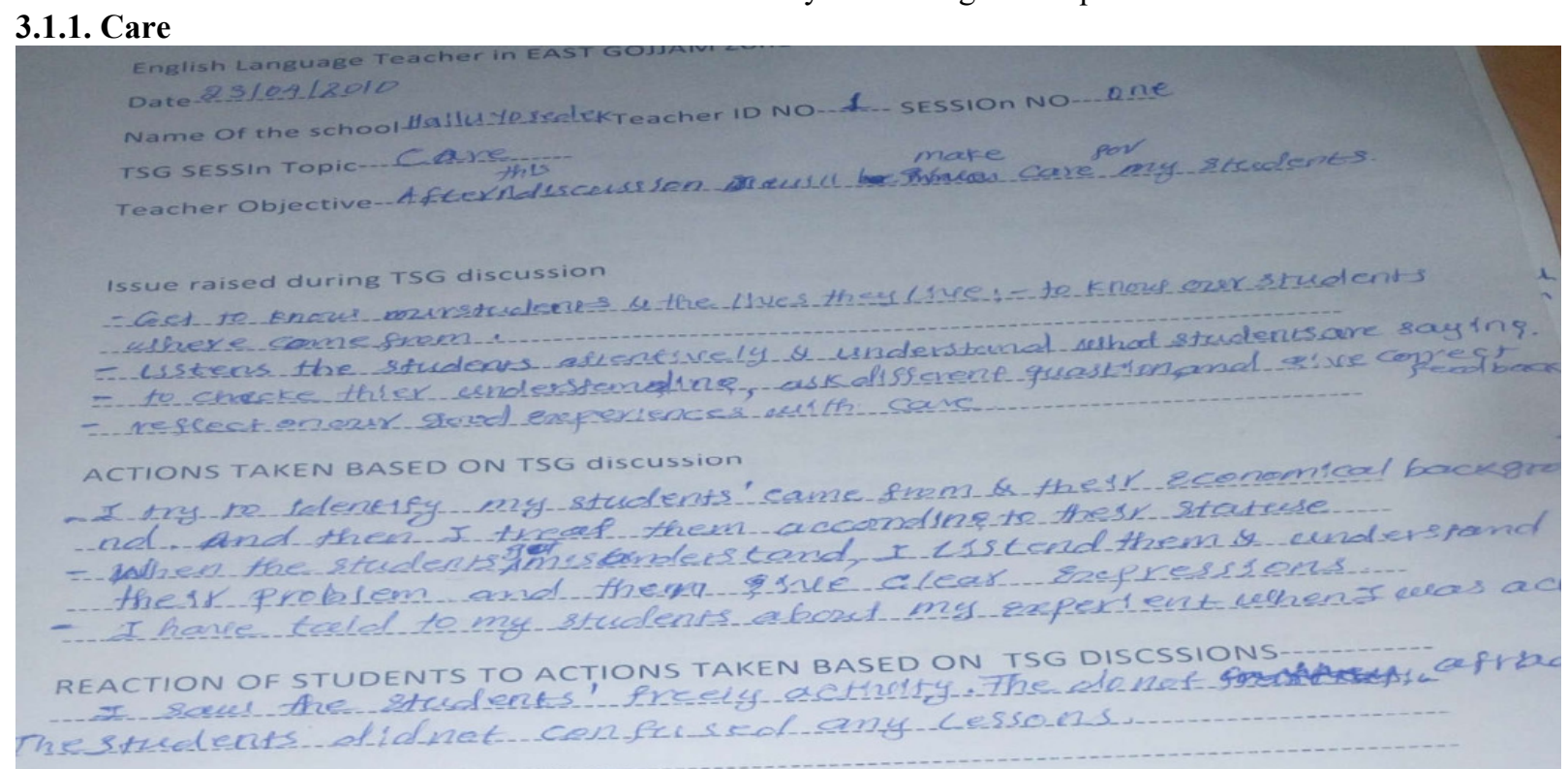

According to Ferguson, R. (2016) teachers who care show concern for students' emotional and academic wellbeing. They develop supportive, personalized relationships with students, cultivate an emotionally safe environment, and respond consistently to students' social, emotional, and academic learning needs.

During the TSG, teachers in all schools relished that they show care to their students but some significant limitations were noticed. But, teachers presumed that most if not all of their students are unwilling to learn though as caring teachers they were expected to hold a positive expectation. Moreover, their treatment of students who were upset and sad was not caring. Accordingly, the teachers were asked to practice strategies of a caring teacher and record its effects in their reflective logs. As shown in a reflective log of teacher 01B from Bichena the TSG helped him in understanding the economical and academical problem of students stating that he told his students about his personal experiences as a student from a poor family. This as reflected by the teacher has helped the students participate freely thereby asking for clarification if confused. Another teacher, 02A from Amanuel reflected that the TSG helped him ask for continuous feedback which he felt improved his relationship with his students. However, in a classroom observation made in Amanuel no 1 primary school, a teacher was disappointed and let students out for not doing a homework.

\subsubsection{Confer}

Teachers who confer encourage and value students' ideas and views. They seek and respect students' thoughts, opinions, and input as part of the learning process. Teachers effectively confer through practices that comprise respecting perspectives of the students, promoting free discussion and inviting input from the students which when practiced foster active learning environment (Ferguson, R., 2016). 


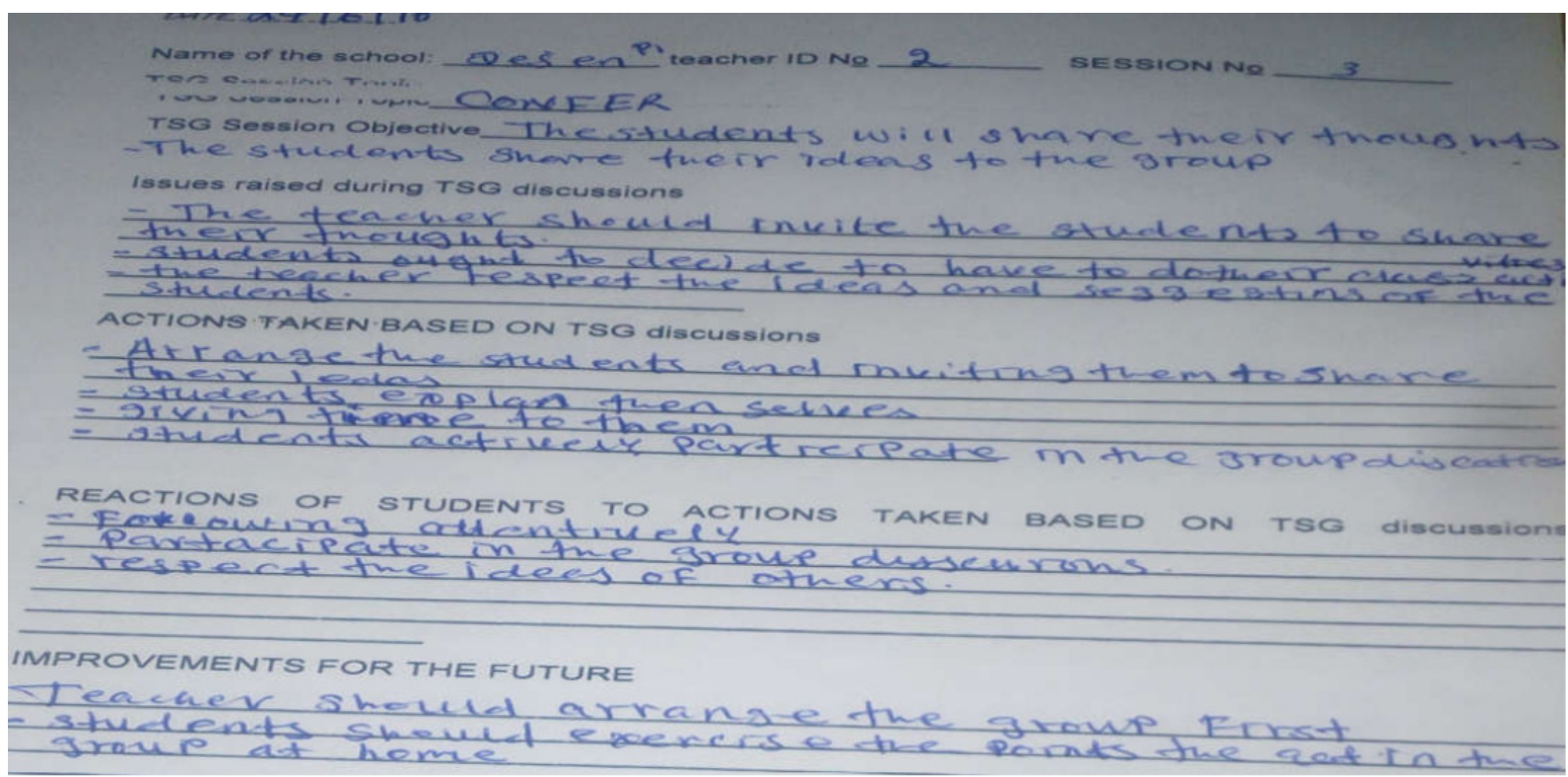

During the TSG, teachers in all schools posited that they discuss how learning will progress. They also stressed that they try to follow up student's engagement during their discussion. However, most of the teachers in all the schools rarely invite students who do not raise to answer. Besides only two teachers one from Dejen and one from Amanuel asserted they would never give incorrect answers while others reiterated the teacher should be seen as knowledgeable all the time.

Hence, the teachers were asked to practice strategies of an empowering (conferring) teacher and record its effects in their reflective logs. As shown in a reflective log of teacher 02D from Dejen the TSG discussion on empowering students helped her in giving more time to students and respect their ideas which resulted in students attentiveness and respectfulness to their peers. A teacher from Amanuel stated that the seriousness of students increased as the teachers adopted strategies of conferring. The classroom observation made in the three schools was indifferent in this regard. All the teachers made efforts to value their students.

\subsubsection{Captivate}

Teachers who captivate, stimulate and maintain student interest by cultivating curiosity and creating inquiry and by making lessons interesting, relevant, and enjoyable (Ferguson, R., 2016). In other words, teachers can effectively captivate their students by designing stimulating lessons and facilitating active participation.

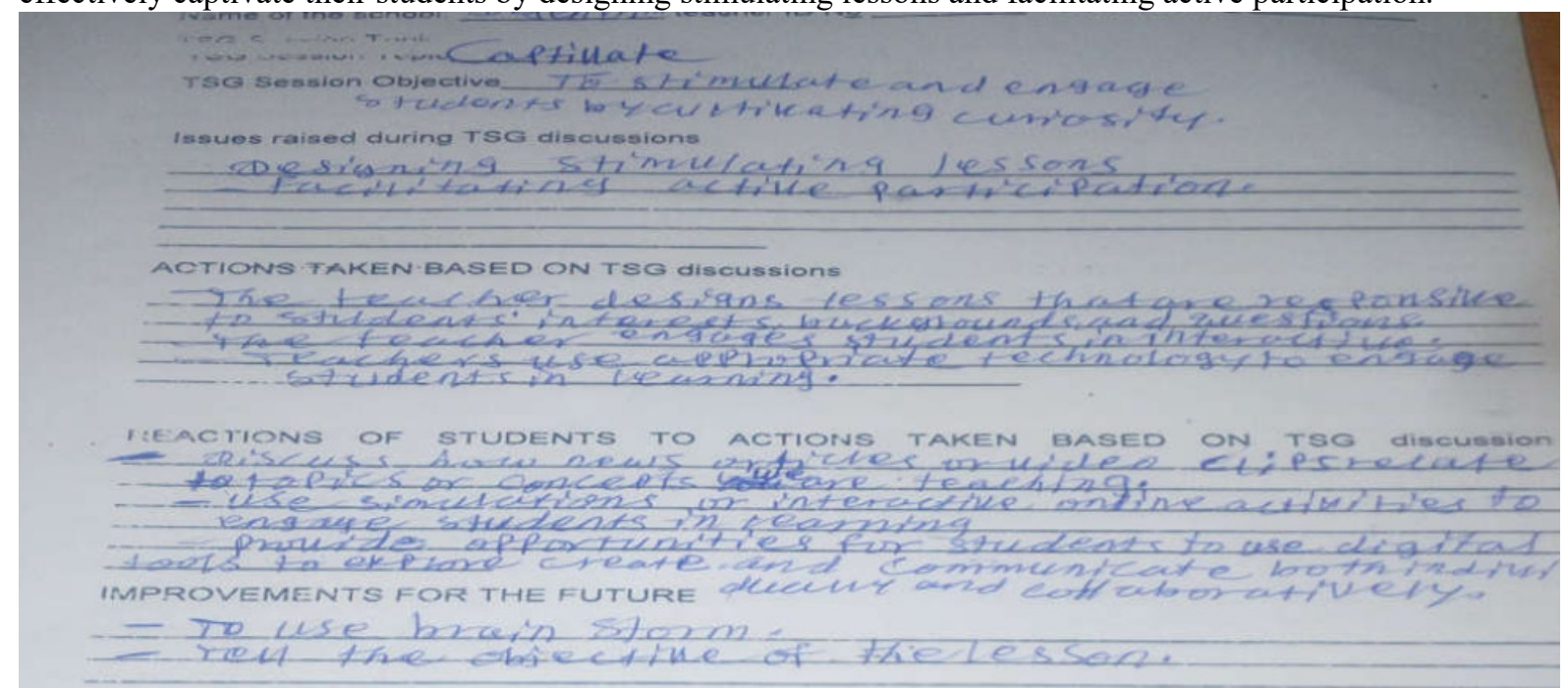

During the TSG carried out, teachers stated that they use a variety of ways of engaging their students admitting students interest to learn is poor. However, because of time constraints and other related factors only active students are highly engaged while others are not captivated during their lesson.

During the TSG discussion in Dejen a teacher stated that:

there are 72 students in one class. Though the contents are bulky and students potential to engage in active learning is unlikely in addition to the unclear teacher guide, he try to raise students curiosity to learn so that they would be engaged. 
Another teacher from Bichena agreed on the challenges but stated that she sometimes tells jokes to initiate students and catch their attention, however these days values given to education are degraded for graduates are hardly employed. Besides, they have to complete the text book.

Accordingly, teachers were asked to practice some of the agreed upon principles of captivating students and record its result in their reflective logs. The teachers indicated that they made efforts to make their lessons engaging and make the lesson interactive by involving the students effectively. The teachers recorded significant improvements on their students engagement. Of the improvements, students participation in brainstorming questions and crafting lesson objectives are eminent.

\subsection{Clarify}

Teachers who clarify help students understand content and resolve confusion (Ferguson, R., 2016). They explain ideas and concepts in a variety of ways, check frequently for understanding, address misconceptions, and provide useful feedback by explaining clearly and expecting areas of difficulty giving multiple explanations for those that frequently cause confusion. Effective teachers in clarifying break down complex tasks, checking for understanding and clearing up confusion, providing constructive, timely, and specific feedback.

During TSG, we learned that the teachers give examples and worksheets and request students to read the book ahead to clarify. Most of the teachers admitted that they rarely anticipate things that might be confusing, while the rare feedback they give lacks specificity and timeliness. Moreover, a teacher from Amanuel primary school stated that all the students may not be clear for some are careless about learning.

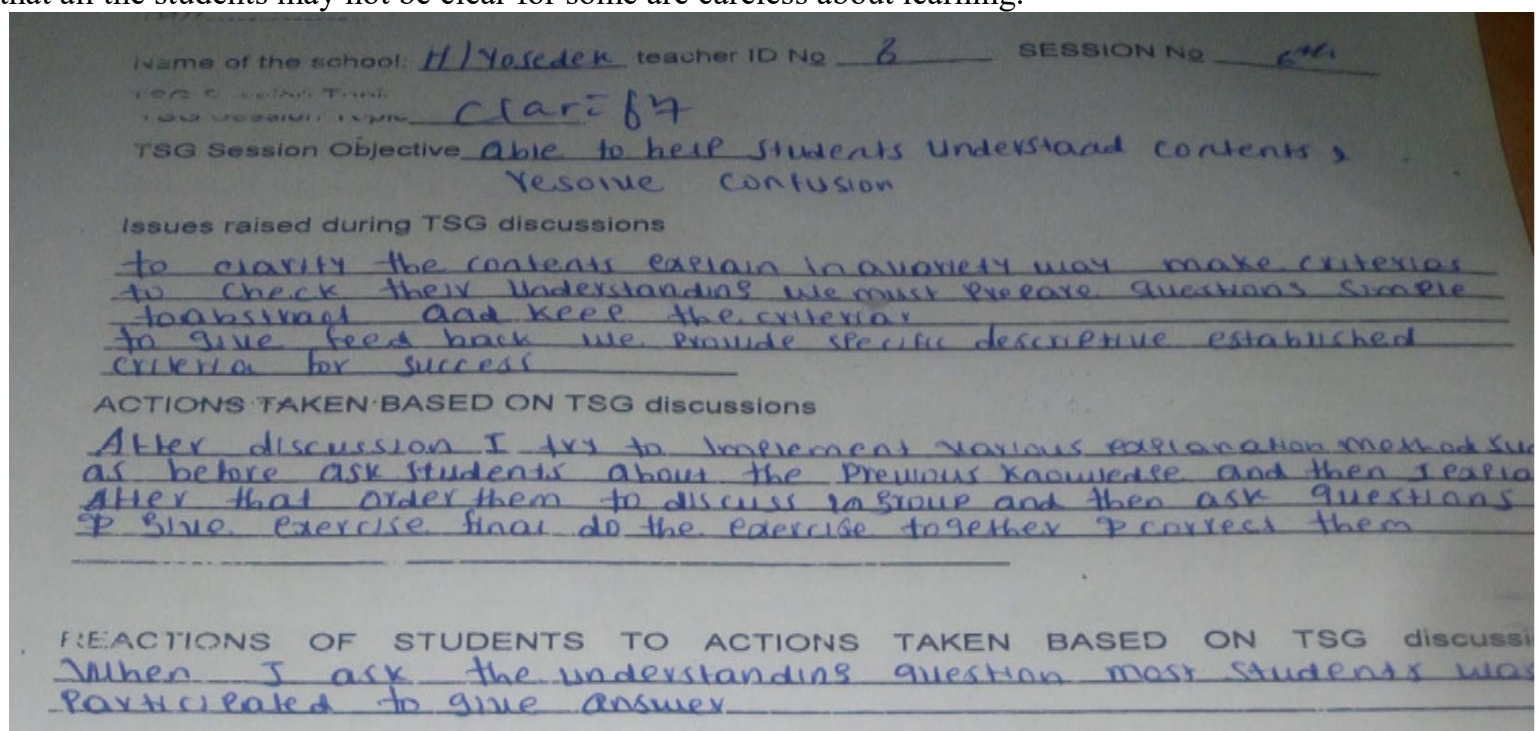

Based on the discussions in each school, the TSG participants were tasked to practice some elements of explaining clearly, checking for understanding and providing constructive feedback and record students responses in their logs.

A teacher from $\mathrm{H} /$ Yosedeq in Bichena reported that most of her students actively participated and answered questions when she practiced clarifying as discussed during TSG. The teacher tried to assess students prior knowledge, give direction and discuss it in groups thereby creating a situation where unclear issues would be clarified in a number of ways and stages. The classroom observations in H/Yosedeq primary school proved that the teacher has adopted the strategies for clarifying. The teacher restated and asked for understanding few times.

\subsubsection{Consolidate}

According to (Ferguson, R., 2016) teachers who consolidate help students integrate and synthesize key ideas. They summarize and make connections in ways that help students see relationships within and across lessons, remember ideas, and build understanding over time. Teachers effectively consolidate by consistently reviewing and summarizing content with students and showing how to connect ideas effectively that is showing how to organize and integrate content to make it easier for students to remember and understand. 


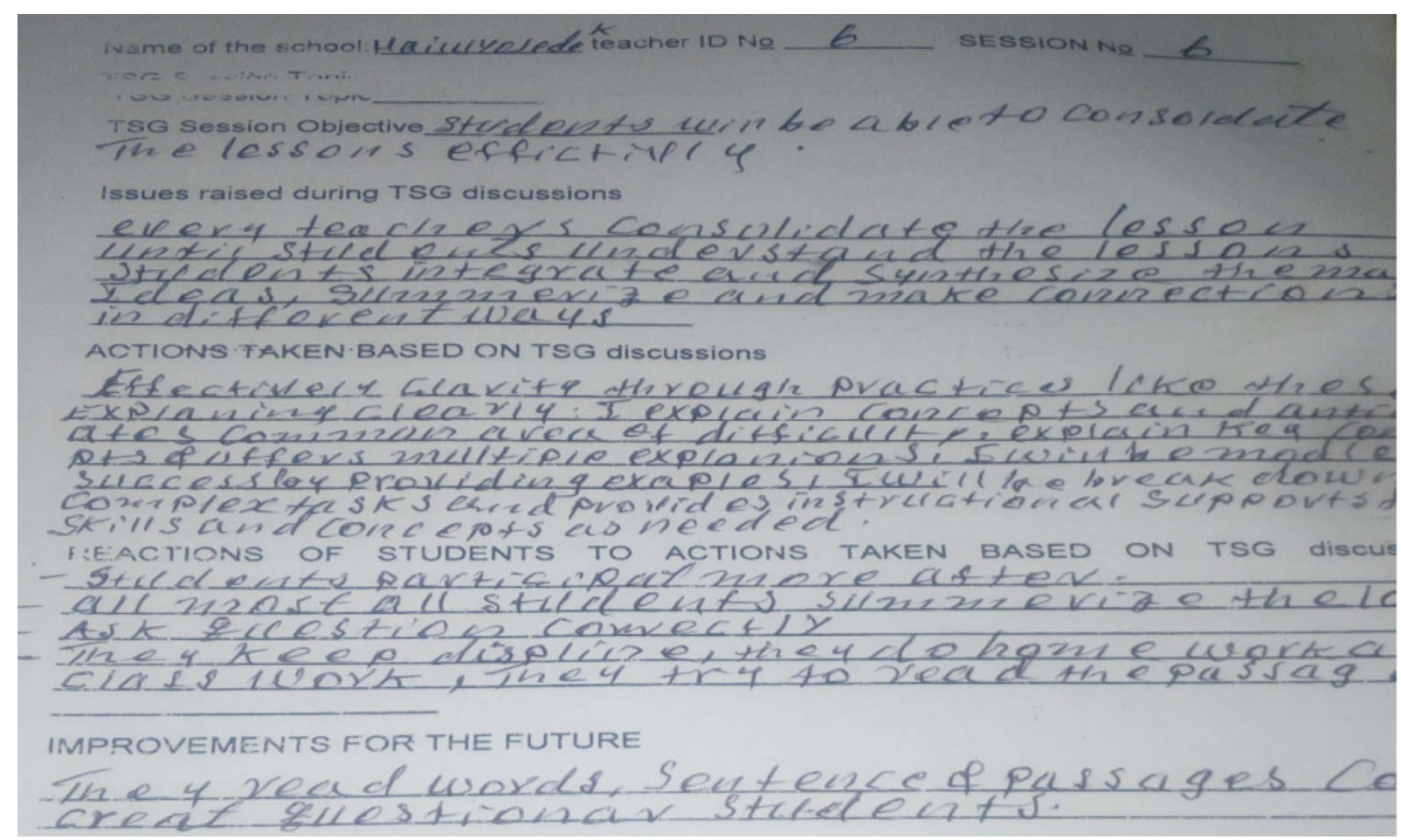

During the TSG, teachers admitted that they make summaries at the end of each lesson. Most of the teachers believe that the textbooks present contents in a connected and integrated way that they may not have to show connections. The teachers in all the schools reported that they hardly request their students to summarize a lesson. Hence, the teachers were asked to request students summarize lessons and report the reactions of students towards the change.

Accordingly teachers observed remarkable change in students' attentiveness and engagement which the teachers attributed to the summarizing questions at the end of the lesson. The teachers reported that all or most of the students become active participants during the lesson when they are asked to summarize the lesson. As stated in the above reflective log, improvements on classroom discipline and performance on classwork was enhanced.

\subsubsection{CHALLENGE}

Teachers who challenge students insist that students persevere and do their best work. They hold students to high academic expectations, encourage persistence, and monitor student effort by pressing for rigorous thinking, for instance by asking probing questions that require students to think deeply, encouraging them to generate original, creative ideas, to strive for high quality work and clearly conveys a belief in their capability, requiring especially those who may tend to be disengaged all students to try hard and communicating that when work is difficult, effort and persistence lead to personal growth and ultimate success (Ferguson, R., 2016). 


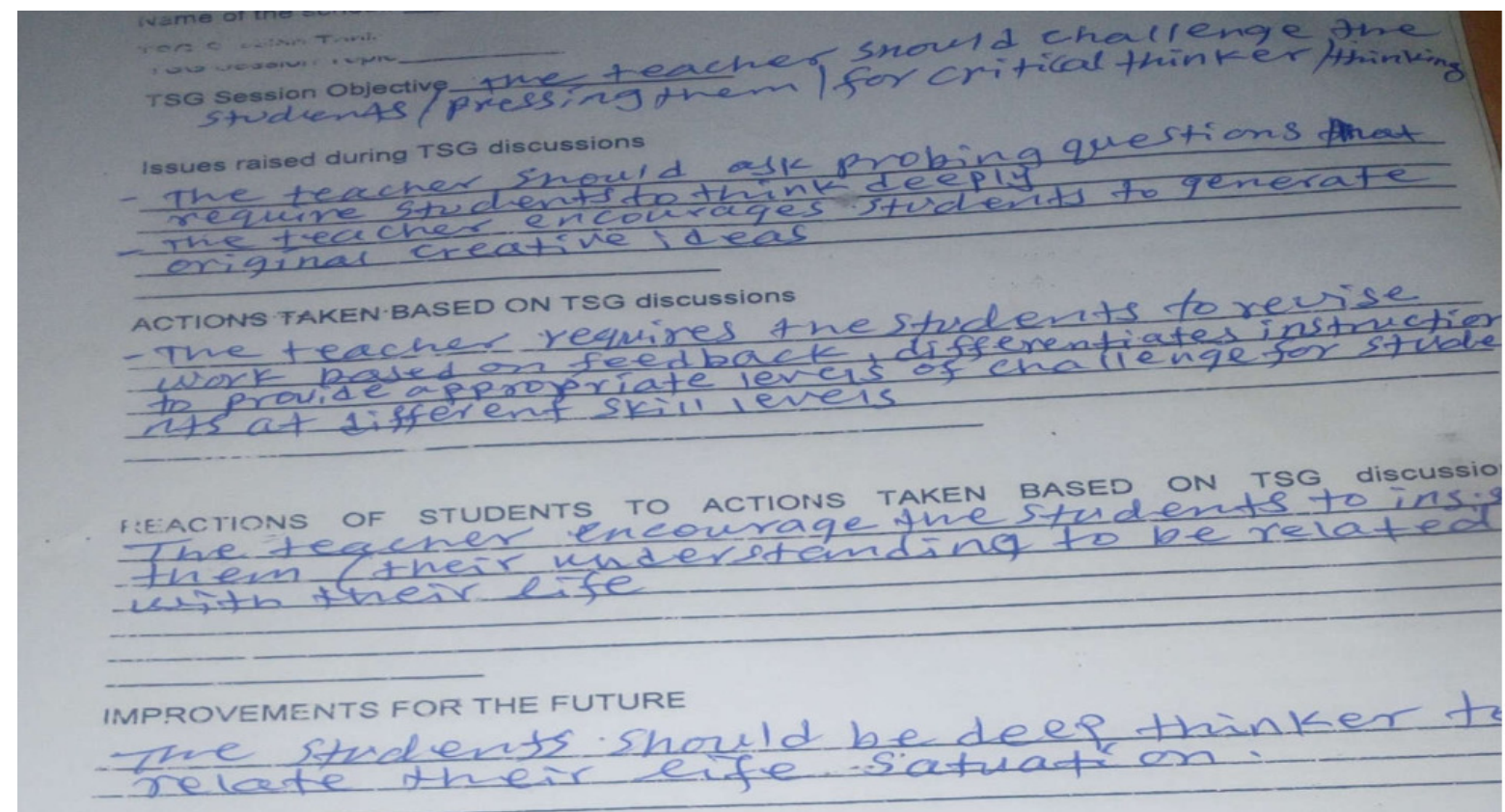

During the TSG, teachers posited that they have varied students in terms of performance. They also stated that all of their students are given chances to solve challenges and given examples to difficult tasks. Besides, one teacher in Amanuel number one primary school usually gifts students who achieve an exceptional score on a yearly basis. This said, the teachers confessed that they do not probe students for critical thinking when they make errors, instead of telling answers themselves. Moreover, they let volunteering students answer giving up on passive ones. Hence, the teachers were requested to challenge every student and consider disengaged students. The adjustments made by TSG participants on the notion of holding high expectation was overwhelming. The teachers reported enthusiasm and desire to work when the teachers insisted on challenging students by probing and pressing for quality work and persistence as the task given becomes demanding. This, as stated by the teachers can be attributed to the trust students got from their teachers.

\subsubsection{Control/ Classroom management}

According to (Ferguson, R., 2016) teachers who are effective at classroom management foster orderly, respectful, and on-task classroom behavior. They create conditions that enable learning, including establishing a positive classroom climate, teaching self-management skills, monitoring student conduct, and redirecting unproductive behavior. In other words, teachers who are exemplary in classroom management run classroom activities smoothly due to materials being readily accessible and time being managed effectively, including during transitions and interruptions. 


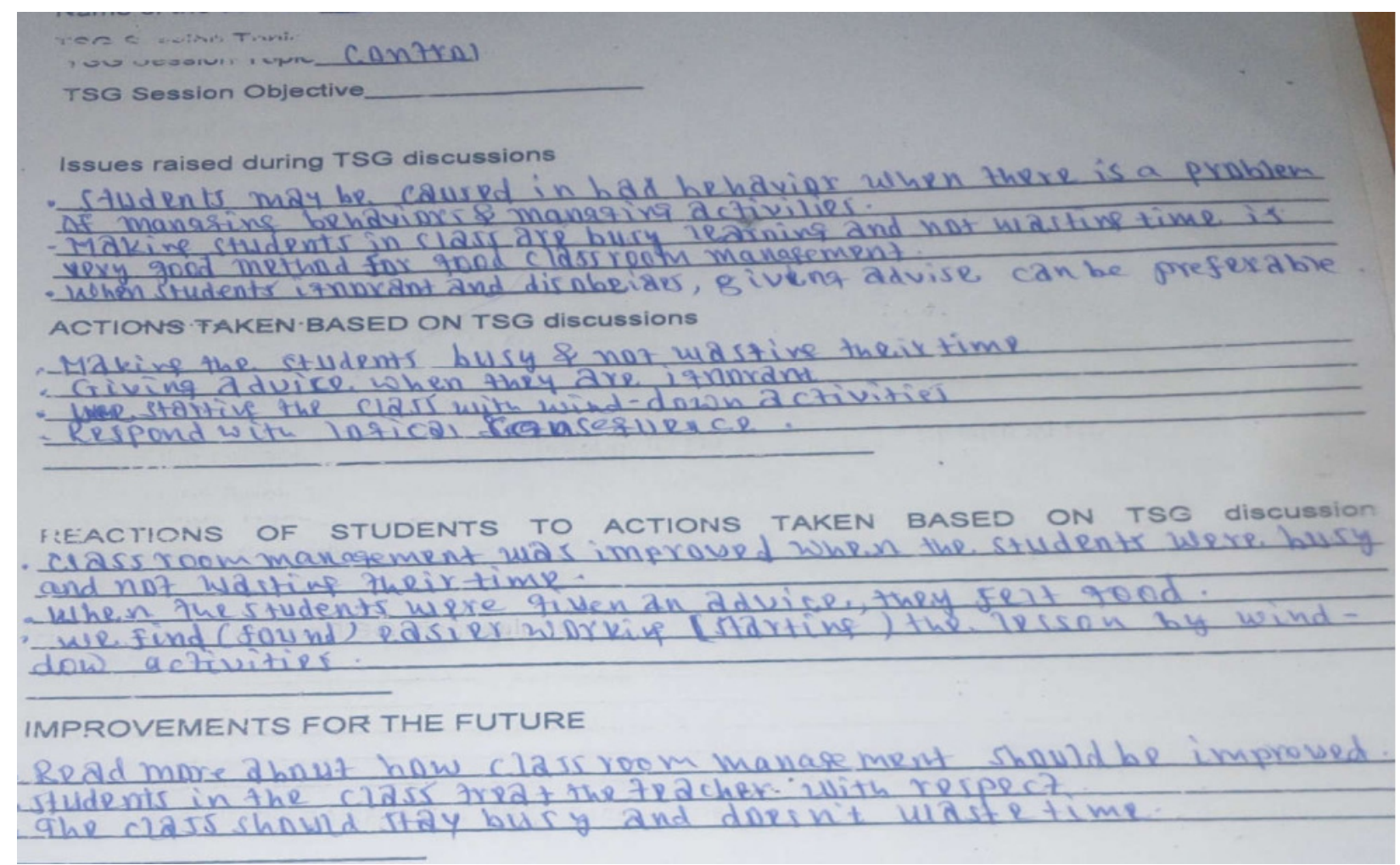

During the TSG, teachers asserted that they set rules at the beginning of the year clearing expectations. Moreover, they stated that they welcome questions all the time. In spite of this, the teachers admitted that students in sometimes class are wasting time during discussions. To that end adjustments comprising managing misbehavior, making students engaged on task and agreeing when to stop a discussion were made by the participants and practiced by each individual teacher. The teachers prepared and used participatory ground rules, asking questions randomly and not the rapporteur alone and a signal to signal stop discussion. The effect of the intervention showed an improvement on students engagement and learning and relationship with their teacher.

\subsection{Discussion}

In this study, a TSG discussion on indicators of effective teaching was used as an intervention to improve teaching effectiveness of English language teachers in four primary schools purposively selected from east Gojjam zone. Moreover, a focus group discussion and reflective logs of the teachers were used as major tools for gathering and evaluating the data as it unfolds. In other words, the extent to which the TSG discussion impacted awareness of teachers on their teaching effectiveness was evaluated through their own weekly reflections and FGDs. 


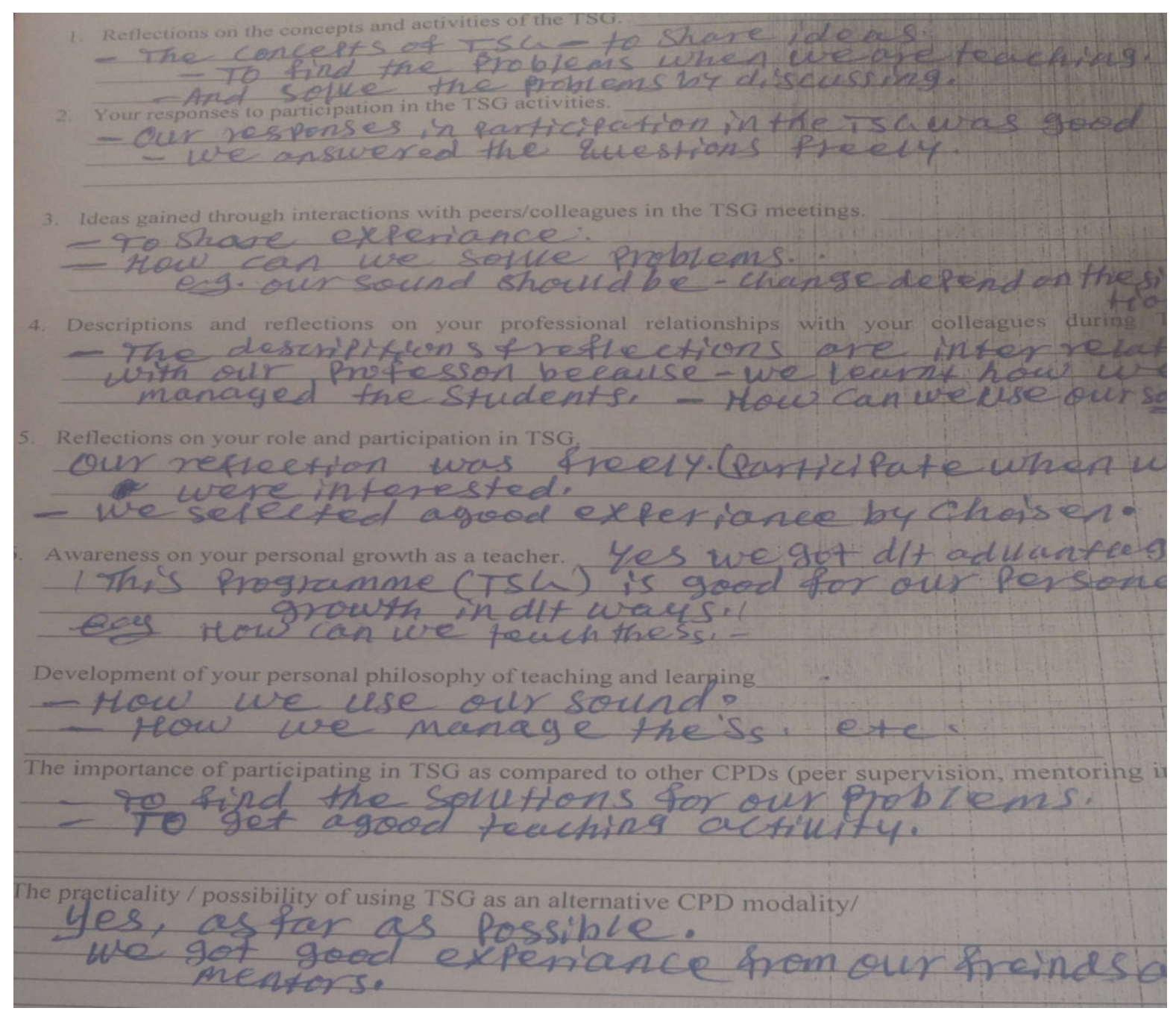

During the FGD in Dejen, teachers made it clear that a TSG has given them a good experience sharing opportunity where participation was at will. For teacher T04D in the school, the topics selected for TSG has addressed some of her limitations on how to catch their student's attention and understanding their problem. Another TSG participant from Amanuel underlined that the participation was a good opportunity in helping teachers open up on their classroom practices to orchestrate an engaging and deep learning classroom environment where all the teachers are posing questions and alternative perspectives on how to solve it. Furthermore, the teachers reported that TSG is an opportunity for teachers to save time because it fosters deep understanding on how to handle tasks in an orderly and timely fashion.

\section{IMPLICATIONS OF THE STUDY}

The purpose of this study was to explore the role of participation in teacher study groups in enhancing the teaching effectiveness of teachers in selected primary schools of East Gojjam zone. More specifically, the study was intended to adapt teacher study group procedures that can enhance teaching effectiveness of teachers. In this study, a total of 16 teachers completed the TSG program. The teachers from primary schools in Dejen, Amanuel and Bichena completed the TSG sessions.

School teachers need to be acculturated to prepare students not only for a changing world but also in a changing world. As Zmuda, Kuklis and Kline (2004) explained, schools need to be built as a competent system, which requires several significant shifts - from unconnected thinking to systems thinking, from an environment of isolation to one of collegiality, from perceived reality to information-driven reality, and from individual autonomy to collective autonomy and collective accountability. Within such a context there is a need for teachers to be lifelong learners who envision continuous learning and improvement. To this end, professional learning has been placed at the forefront.

In line with this, from the FGDs and reflective logs, it is evident that the teacher's collegiality and open mindedness to engage in a dialogic TSG has improved significantly. Moreover, as reflected by the teachers, their teaching effectiveness (as indicated by tripod 7C indicators) has improved significantly due to participation in TSG. Classroom observations and reflective logs of the participant teachers proved that teachers have adopted 
strategies of caring, clarifying, conferring, captivating, consolidating, challenging and controlling to enhance their own teaching effectiveness. However, further studies should confirm the viability of TSG discussion focused on teaching effectiveness before it is considered as an alternative CPD modality.

\section{References}

Akerson, V., McDuffie, A.\& Roth, A. (2002).The elementary science teacher as researcher. International Conference of the Association for the Education of Teachers in Science.

Borko, H. (2004). Professional development and teacher learning: Mapping the terrain. Educational Researcher, 33(8), 3-15.

Cayuso, E., Fegan, C., \& McAlister, D. (2004). Designing Teacher Study Groups: a Guide for Success. Maupin House Publishing.

Clair, N. (1998). Teacher Study Groups: Persistent Questions in a Promising Approach. Tesol Quarterly Vol. 32(3)

Clarke, D., \& Hollingsworth, H. (2002). Elaborating a model of teacher professional growth. Teaching \& Teacher Education, 18(8), 947-967.

Cochran-Smith, M., \& Lytle, S. (1999). The teacher research movement: A decade later. Educational Researcher, $28(7), 15-25$.

Creswell, J. W. (2007). Qualitative inquiry \& research design: Choosing among five approaches. (2nd ed.). Thousand Oaks, CA: Sage

Ferguson, R. and Danielson, C. (2013). How Framework for Teaching and Tripod 7Cs Evidence Distinguish Key Components of Effective Teaching.

Ferguson, R. (2016). A Guide to Tripod's 7Cs Framework of Effective Teaching: A Practical Guide for Improving Teaching \& Learning. www.tripoded.com.

Holden, G. (2002). Towards a learning community: The role of mentoring in teacher-led school improvement. Journal of In-Service Education, 28(1), 9-22

Hui-chin Yeh. (2005). Teacher Study Group as a vehicle to strengthen EFL teacher's professional identity and voice. Asian EFL journal, 7(4), 50-73.

MoE. (2009). Continuous Professional Development for Primary and Secondary School Teachers, Leaders and Supervisors in Ethiopia: The Framework. MoE, Ethiopia

Moreno, G., Palencia, S. (2001). Teacher Communities as a means to support Professional Development. Thesis. Bogotá: Universidad Distrital "Francisco José de Caldas"

Sparks, D. (2002). Designing powerful staff development for teachers and principals. Oxford, OH: National Staff Development Council

Villegas-Reimers, E. (2003). Teachers Professional Development: An International Review of Literature. Paris: International Institute for Educational Planning. Retrieved on June 2o, 2013 from: http://www.unesco.org/iiep.

Westwood, P. (2008). What teachers need to know about teaching methods. ACER Press.

Yi-Ching Huang (2007). How teachers develop their professional knowledge in English study group in Taiwan. Educational Research and Review Vol. 2 (3) 36-45

Yin, R. K. (2009). Case study research: Design and methods (4 ${ }^{\text {th }}$ ed.). Washington, DC: Sage.

Valerie, H. And Magdalena, K., (2008). The Challenges of Researching Language Teachers: What Research Manuals Don't Tell Us. Language Teaching Research, 12(4): 495-513. 